Achieving Compliance With The World Anti-Doping Code: Learning From The Implementation Of Another International Agreement

Stacie Gray

School of Sport, Exercise and Health Sciences, Loughborough University, Loughborough, LE11 3TU, UK.

s.j.gray2@lboro.ac.uk $+447967446168$ 


\title{
Achieving Compliance With The World Anti-Doping Code: Learning From The Implementation Of Another International Agreement
}

\begin{abstract}
The scale of the compliance problem that the World Anti-Doping Agency (WADA) faces was recently highlighted by the exposure of institutionalised doping in Russia and the series of doping scandals within athletics. The article aims to analyse the problems of achieving compliance with the World Anti-Doping Code. Specifically, the article explores the techniques for, and problems of, achieving compliance with the Code and a similar international agreement. The chosen agreement is the UN Convention Against Transnational Organised Crime, with a specific focus upon antimoney laundering. The anti-doping and anti-money laundering regimes were analysed to identify the range of strategies used to achieve (or at least enhance) the level of compliance with the respective international convention. The anti-money laundering strategies were also evaluated to assess their effectiveness as a way of generating ideas for improving compliance with the WADA Code. To analyse compliance, three inter-related bodies of theory were used: regime theory, implementation theory and Mitchell and Chayes' (1995) compliance system. Qualitative document analysis was used to analyse documents published by relevant organisations. Additionally, semistructured interviews were conducted with senior staff members responsible for monitoring compliance at the international and UK domestic level. The results identified a range of strategies used to achieve compliance, including sanctions, random monitoring mechanisms and whistleblowing. It is concluded that the identified strategies have had modest and variable success in improving compliance, yet have the potential to address the problems of achieving compliance with the 2015 WADA Code.
\end{abstract}

Key words: Doping, anti-doping policy, compliance, 2015 World Anti-Doping Code 


\section{Introduction}

In 2003, the World Anti-Doping Agency (WADA) introduced the World Anti-Doping Code (the Code) as the core document designed to globally harmonise anti-doping rules, regulations and policies amongst public authorities and sporting organisations. Since its inception, the Code has undergone two revisions, the most recent being the 2015 Code. The revision process for the 2021 Code is currently underway. Despite the extensive endorsement of the Code by governments and sport organisations, organised doping in sport and variability in Code compliance have continued to be major problems. Recently, a series of high profile doping scandals have demonstrated the scale of non-compliance. Of significance was the 2015 revelation of institutionalised doping in Russia, which WADA described as one of the 'most destabilising incidents for sports in recent memory' (WADA 2016, p. 5). Whereas Russia has displayed subversive behaviour, in countries such as Jamaica and Kenya, compliance is hindered by severe capacity and resource limitations. Additional scandals have highlighted the scale of non-compliance amongst individual athletes and sports. In 2012, it was revealed that Lance Armstrong, seven times Tour de France champion, had persistently doped throughout most of his career (Hardie et al 2012). The recurrence of major doping scandals has placed the issue of compliance at the forefront of the anti-doping regime. Furthermore, the repeated announcement of doping violations by high-profile athletes (many of whom have successfully passed regular doping tests throughout their careers) has raised questions regarding the effectiveness of global anti-doping efforts and WADA's compliance system (Hanstad and Houlihan 2015). In light of the current situation, this article aims to analyse the problems of achieving compliance with the 2015 Code.

Although WADA and its major partners face challenges in terms of achieving compliance, many of the challenges are not unique to the anti-doping regime; they are general problems that hinder the implementation of, and compliance with, international agreements across various sectors. Numerous international agreements have struggled to foster a global commitment towards compliance. To use the human rights sector as an example, considerable variations exist in terms of state compliance (Downs and Trento 2004). Although Japan has ratified the Convention on the 
Elimination of All Forms of Discrimination Against Women, the Japanese government has generated little momentum towards the elimination of gender discrimination. In the 2017 World Economic Forum (WEF) Global Gender Gap Index, Japan ranked $113^{\text {th }}$ out of 144 . In contrast, developing countries such as Rwanda, Uganda and Bangladesh ranked $4^{\text {th }}, 45^{\text {th }}$ and $46^{\text {th }}$ respectively (WEF 2017). In addition to facing similar compliance challenges, international regimes exhibit a diverse range of compliance mechanisms. Consequently, comparative analysis of international agreements and their respective policy regimes provides an opportunity to develop a deeper understanding of the techniques for achieving compliance (Downs and Trento 2004).

Although lessons may be learnt from the implementation of other international agreements, few studies have compared Code compliance with the compliance challenges faced by signatories of a similar international agreement. To begin to address this research gap and to explore the potential value of examining the ways in which other international agreements meet the challenges of achieving compliance, the study aims to explore strategies for strengthening compliance with the Code through an analysis of a similar international agreement. The chosen international agreement is the United Nations Convention Against Transnational Organised Crime (UNTOC), with a specific focus upon anti-money laundering. Similar to the Code, the UNTOC represents a top-down agreement that focuses upon changing the behaviours of individuals within governments and non-governmental organisations. The antimoney laundering regime addresses criminal activity and aims to encourage people to observe the law, particularly with regard to the acceptance and transfer of money from questionable sources. Doping in sport may be described as a semi-criminal activity. Whilst only a small number of countries have criminalised doping in sport (examples include Austria, Spain and Italy), doping is part of a wider criminal network including illegal drug production, trafficking and distribution. The effectiveness of the strategies used in the anti-money laundering regime and their potential to generate ideas for improving compliance with the Code, will also be assessed. Although attention will be paid to the anti-money laundering regime, this article was part of a larger comparative study that also analysed the UN Convention on the Rights of the Child and the UN Convention on the Rights of Persons with 
Disabilities. Where appropriate, references will be made to the child rights and disability rights regimes.

\section{Methodology}

The research adopted a cross-sectoral, comparative case study approach. Components of the anti-doping and anti-money laundering regime's compliance systems were analysed and compared to develop a deeper understanding of the problems of, and techniques for, achieving compliance. Drawing upon insights from the anti-money laundering regime, strategies to enhance Code compliance were recommended. Methodological triangulation (in this case qualitative document analysis and semistructured interviews) was used to corroborate evidence and enhance the credibility of the research findings. The role of documents is twofold: 'they appear as both receptacles of content, and as active agents in networks or action' (Prior 2008, p. 822). As international agreements, documents such as the Code and the Financial Action Task Force (FATF) Recommendations demonstrate agency; they commit signatories to specific action, contribute towards the direction of behaviours and support organisational pathways (Cooren 2004). To heighten the level of document authenticity, public documents were sourced through the official websites of relevant organisations, including WADA, the International Olympic Committee (IOC), the United Nations, the FATF and the IMF (International Monetary Fund). Academic articles were predominantly derived from peer-reviewed journals that covered antidoping policy.

Semi-structured interviews provided rich data that pertained to the participant's experiences and viewpoints regarding compliance. An interview guide comprising open ended, non-leading questions was developed prior to the interviews. Open-ended questions enabled interviewees to provide narratives in their own words, whilst probes elicited elaborate responses (Bryman 2008). In light of the study's focus upon the managerial challenges of implementing and achieving compliance with the Code and the FATF Recommendations, selection criteria was identified to ensure that the interviewees had sufficient policy knowledge to provide a rich and accurate narrative. The first criterion was staff that hold a senior position within the organisation. The second was someone who had been in the role for a significant period of time (five 
years or more). The final criterion was someone with a direct strategic responsibility for monitoring compliance at the international or domestic level. Senior staff from the following organisations participated in interviews during 2017: WADA, Anti-Doping Norway (ADN), Anti-Doping Authority Netherlands (Dutch Doping Authority), UK Anti-Doping (UKAD), the Japan Anti-Doping Agency (JADA), the Canadian Centre for Ethics in Sport (CCES), the FATF and the Royal United Services Institute (RUSI). The interview transcripts and documents were analysed using Braun and Clarke's (2006) six phases of thematic analysis: familiarising yourself with the data; generating initial codes; searching for themes; reviewing themes; defining / naming themes; and producing the report. Additionally, interview extracts were embedded into the analysis to corroborate documentary evidence and provide a compelling argument that was specific to the research aim.

\section{Summary of Previous Anti-Doping Compliance Literature}

A broad range of research has investigated anti-doping policy and regulations. Focusing upon the international and Canadian context, Ritchie and Jackson (2014) found that external crises and scandals, particularly those which generated public reaction, prompted significant policy reforms within the international and Canadian anti-doping regimes. Consequently, the history of anti-doping policy is largely reactive and politically driven. This finding contradicts the frequent assertion by antidoping actors that ethical and proactive decision-making guides anti-doping policy. National anti-doping policy is also influenced by the macro and micro context; both contexts have explained gaps between global anti-doping policy requirements and domestic implementation in Slovenia. Macro reasons were linked to Slovenia's policy traditions and value orientations, whilst micro explanations included an unwillingness to implement change and capacity constraints within Slovenia's domestic institutions (Lipicer and McArdle 2014).

The reactions of anti-doping actors towards institutionalising anti-doping policy have also been analysed. Wagner and Hanstad (2011) investigated why, in contrast to Sweden, Norway and Denmark chose to create an independent national anti-doping agency. One factor that explained the various approaches to anti-doping in elite sport was the relationship between national and global sport cultures; compared with 
Norway and Denmark, the status of anti-doping in Sweden displays more autonomy. With reference to the UK's decision to implement an independent national antidoping organisation (NADO), drivers for change included the need to reduce potential conflicts of interest and enhance the integrity of sport (Batt 2011). Wagner (2011) examined the contrasting anti-doping approaches of International Federations (IFs), specifically the International Association of Athletics Federations (IAAF) and the Fédération Internationale de Football Association (FIFA). The contrasting anti-doping strategies of the IAAF and FIFA were partly attributed to the varied attitudes of the organisations towards doping. On the one hand, the IAAF recognised doping as an endogenous problem and through intensified efforts, established itself as an antidoping entrepreneur. On the other hand, FIFA's slow acceptance of the doping issue resulted in reluctant anti-doping efforts.

With reference to compliance, research (Bloodworth and McNamee 2010, Huybers and Mazanov 2012, Overbye et al 2013) has investigated athletes' compliance with anti-doping regulations. Specifically, the circumstances that influence athletes' hypothetical decisions to dope were examined. A range of factors including sporting bans, social anti-doping norms, personal moral values, economic pressures, enhanced injury recovery and significant others, influenced athlete's doping decisions. Consequently, diversified anti-doping prevention strategies are essential to address the variety of factors behind non-compliance amongst athletes. Fewer studies have explored the challenges of achieving, and potential strategies to enhance, signatory compliance with the Code and the UNESCO Convention Against Doping in Sport. Where organisational and state compliance is concerned, it is important to distinguish between adherence (ratification), implementation and compliance. Trachtman (2010, p. 4) defined adherence as the decision at domestic level to execute the 'international legal rule as a national measure'. Extensive and rapid adherence of the Code occurred amongst IFs, international sport organisations and event organisers. Within five years, more than 100 IFs were signatories. The shift from adherence to implementation is indicated when primary actors (including governments, IFs and event organisers), commit resources. Resources include inputs such as budget creation and staff appointments, in addition to outputs such as an established programme for doping control and anti-doping education. WADA and UNESCO primarily use ratification numbers and implementation outputs as indicators of success. However, Code 
signatory and testing numbers have hidden inadequate levels of compliance amongst some governments and anti-doping organisations (ADOs) (Houlihan 2013). Compliance is understood as a deep, intense commitment towards reaching the goal of drug-free sport (Hanstad and Houlihan 2015).

Arguably, Houlihan's (2013) research is one of the most comprehensive studies to investigate Code compliance. Houlihan evaluated the effectiveness of procedures used to measure and enhance compliance with the 2009 Code, specifically biennial surveys, Independent Observer (IO) Reports and the process by which WADA monitors the decisions of NADOs. Whereas the IO reports were perceived as important mechanisms that verify the content of self-report surveys, the surveys were more effective at gauging the breadth, rather than depth, of compliance. Potential action areas to improve the monitoring of, and compliance with, the Code included domestic lobbying, legislation to address manufacturing and trafficking, improved governance amongst anti-doping actors, norm internalisation and stronger sanctions. More recently, Hanstad and Houlihan (2015) evaluated the extent to which bilateral agreements can achieve enhanced levels of compliance amongst ADOs. Bilateralism's potential contribution was demonstrated through Norway and China's long-term agreement. Following close collaborations with Norway, China successfully established a NADO and developed doping control procedures that were in line with international standards. However, the effectiveness of bilateral agreements is dependent upon a supportive international policy environment.

Although the anti-doping regime has undergone numerous policy developments in recent years, including the introduction of the 2015 Code, implementation variations and low levels of compliance have undermined the regime's effectiveness. To demonstrate the scale of inefficient doping controls, in their survey of 202 National Olympic Committees (NOCs), Hanstad and Loland (2005) found that less than half of the NOCs conducted anti-doping tests on their own athletes. Furthermore, only 20 NOCs demonstrated 'good' anti-doping work. 'Good' criteria included ISO Certification, conducting out-of-competition tests for WADA or a reasonable number of efficient controls. More recently, at the Rio 2016 Summer Olympic Games, 4,125 out of 11,470 confirmed entrants had no record of testing during 2016 (IO Report 2016). Additionally, the extent of non-compliance has been highlighted through 
numerous high profile doping cases, including the revelation of institutionalised doping in Russia. Consequently, significant progress and reforms are necessary if WADA is to achieve its goal of global harmonisation (Müller 2017). The scale of the current compliance problem, combined with the lack of research in this area, has created a need for further investigation into the problems of, and techniques for, achieving Code compliance.

\section{Analytical Frameworks}

To analyse compliance and to provide a robust basis for comparison, three interrelated bodies of theory were used: regime theory, implementation theory and Mitchell and Chayes' (1995) compliance system. Krasner (1982, p. 186) defined international regimes as 'sets of implicit or explicit principles, norms, rules and decision-making procedures around which actors' expectations converge in a given area'. Policy regimes, whether formal or informal, are purposely formulated on a global or regional scale to address areas of concern within distinct political domains. Examples include the International Trade Regime that addresses economic issues, the Homeland Security regime that addresses security issues and the Ozone Layer regime that is concerned with international environmental issues (Guo and Teng 2012). As an analytical framework, regime theory provides a useful opportunity to explore the implicit rules and norms that govern cooperation and behaviours, including doping and compliance. The breadth of regime theory also enables the integration of implementation theory and Mitchell and Chayes' compliance system, both of which provide a more focused analysis of the structures and processes of compliance.

International agreements and regimes are put into practice through implementation processes. Additionally, implementation is generally a critical step towards compliance (Raustiala and Slaughter 2013). Top-down implementation theory emphasises the role of a central authority such as the government or an international agency. Beginning with the formation of policy objectives, implementation is believed to occur in a hierarchical fashion. The approach focuses upon developing control programmes to reduce deviation from the central actor's goals (Gunn 1978). In contrast, bottom-up implementation theory acknowledges the complex set of interactions created by organisational multiplicity. Hjern and Porter (1983) introduced 
the concept of implementation structures (structures that comprise groups of organisations and actors) and suggested that programmes are implemented through a matrix or network of organisational pools, rather than one single organisation. Bottom-up implementation theory's focus upon networks provides an opportunity to explore the interactions between, and interdependency of, policy regime actors at various levels of implementation. Bottom-up implementation theory also contributes towards an enhanced understanding of compliance. Lipsky (1978) identified working environment pressures (inadequate resources, large caseloads, client unpredictability and professional norms) as key factors that hinder the ability of local level officials to meet the implementation and compliance expectations of senior policy-workers. To alleviate working environment pressures, front line employees develop coping methods, including processing in ways that are relatively stereotyped and routine. Such coping mechanisms become the public policies that street level bureaucrats carry out. Within the anti-doping regime, WADA is recognised as the international standard setter and implementation of the Code occurs through a top-down approach (Houlihan 2013). For example, WADA is reliant upon IFs to institutionalise antidoping norms within their respective sports. In turn, IFs are dependent upon national federations to institutionalise norms and regulate sport at the national level. Similarly, the UNTOC reflects a top-down approach to implementation; international standards are translated from the global, to national, to local levels. Although the FATF operates at the core of the anti-money laundering regime practicality has meant that private actors operate at the forefront. Consequently, in contrast to the ideal conceptualisation of top-down implementation, the anti-money laundering regime is largely dependent upon 'front line employees', specifically those within financial institutions, to implement the UNTOC, the FATF Recommendations and ensure compliance (Tsingou 2010).

Houlihan (2013, p. 271) defined a compliance system as the 'matrix of actors, relationships, values, expectations and actions that are encapsulated within the Code rules'. Mitchell and Chayes (1995) suggested that a compliance system comprises three elements: a primary rule system, a compliance information system and a noncompliance response system. The primary rule system refers to the rules, procedures and actors, and fulfills the purpose of determining who will be regulated and through what methods. The compliance information system aims to guarantee the highest 
levels of transparency, ensure that high quality, relevant data is collected, and that all data is rigorously analysed and widely circulated. The non-compliance response system comprises the actors, processes and rules that govern the formal and informal responses used to encourage non-compliant actors to comply. The compliance system is a useful analytical framework that focuses upon the impact that endogenous regime factors have upon compliance. To demonstrate the compliance system's significance, a recent study (Müller 2017) identified improvements to the anti-doping regime's compliance system as a necessary component to achieve deeper levels of compliance.

\section{Research Findings and Discussion}

The study identified three recurrent factors that have hindered compliance with the Code and the FATF Recommendations: the top-down approach to implementation, cultural variations and resource constraints.

\section{Top-Down Approach to Implementation}

The first theme to recur was the adoption of a top-down approach to implementation by the anti-doping and anti-money laundering regimes. WADA represents a global hybrid public-private entity that operates at the core of the anti-doping regime and is recognised as the international standard setter. Together, the Code and the UNESCO Convention Against Doping in Sport create a global regulatory structure for antidoping efforts and represent the primary rule system. WADA describes the Code as the core document that globally harmonises anti-doping rules, regulations and policies amongst public authorities and sporting organisations. Government commitment to the Code is signified through ratification of the UNESCO Convention Against Doping in Sport. Consequently, the anti-doping regime's primary rule system leverages soft (non-legally binding) law through the Code, and hard (legally binding) law through the UNESCO Convention (WADA 2016). In comparison, the FATF is an intergovernmental organisation (IGO) that operates at the core of the anti-money laundering regime. In line with the characteristics of IGOs, the FATF was created by nation states to address a specific issue (money-laundering) and primarily comprises member states (currently thirty-five member states and two regional organisations). 
The FATF is a policy making body whose purpose is to establish anti-money laundering standards, encourage effective implementation and engender political commitment towards national legislative and regulatory reform. Empowered by the UNTOC, which encourages state parties to use relevant initiatives of anti-money laundering organisations, the FATF compiled 40 Recommendations to harmonise anti-money laundering standards and provide countries with an implementation framework. Similar to the Code, the FATF Recommendations are characterised as soft law. Nevertheless, the anti-money laundering regime has acknowledged the FATF Recommendations as the international standard (FATF 2018).

Although the anti-doping and anti-money laundering regimes have developed clear top-down implementation frameworks, the logistical challenge of implementation and monitoring compliance transcends the capacities of the core actors, specifically WADA and the FATF. In contrast to Gunn's (1978) ideal conceptualisation of topdown implementation, both regimes are characterised by, and core actors dependent upon, an extensive network of organisations. The range of actors involved in the antidoping regime is highlighted through Article 20 of the Code, which outlines the responsibilities of Code signatories, including the IOC, International Paralympic Committee, National Olympic / Paralympic Committees, IFs, NADOs and major event organisers. Articles 21 - 22 identify additional stakeholders; athlete support personnel, regional anti-doping organisations and governments (WADA Code 2015). Due to the number of actors involved, WADA faces the challenge of ensuring that a commitment towards anti-doping is sustained at all levels of implementation. Similarly, the FATF is dependent upon an extensive network of actors to implement and monitor compliance with the FATF Recommendations. The network includes international organisations such as the World Bank (a specialised independent body of the UN), the IMF (an international intergovernmental organisation), and national organisations including financial institutions, financial intelligence units, financial regulatory bodies and relevant non-financial businesses (FATF 2018). This finding was also evident in the child rights and disability rights regimes; the $\mathrm{UN}$ is largely dependent upon the ability of governments and other actors to effectively institutionalise international norms and practices at national and local levels. 
The extent to which WADA and the FATF are dependent upon other organisations varies, particularly with regard to the non-compliance response system. Although sanctions are available in the anti-doping regime, WADA's powers are limited to withdrawing laboratory accreditation. Consequently, WADA is dependent upon organisations such as the IOC, IPC and IFs to impose international sanctions. To maintain credibility, WADA also faces the challenge of ensuring that the sanctions imposed by relevant ADOs are consistent with the Code (Efverström et al 2016). Under Article 20.1.8 of the Code, the IOC is required to only accept Olympic Game bids from countries that are Code compliant. Similarly, under Article 20.3.11, IFs are required to award World Championships to countries with Code compliant NADOs (WADA Code 2015). Despite the outcomes of the McLaren report, the hosting rights for the 2021 International Biathlon Union World Championships were awarded to Russia. Referring to Article 20.3.11, Yaya Yamamoto, JADA Senior Manager criticised the anti-doping regime for 'failing in terms of the response to noncompliance by IFs' (JADA Interview 2017). WADA's lack of independence and inability to impose sanctions upon non-compliant parties was emphasised following the revelation of institutionalised doping in Russia. Informed by the McLaren report, WADA recommended that the IOC and IPC ban Russia from the Rio 2016 Summer Olympic Games. In line with WADA's recommendation, the IPC imposed a blanket ban upon Russian athletes at the Rio Paralympics. In contrast, the IOC delegated the responsibility for imposing bans to IFs (IOC 2016). Variations in rule enforcement undermine the legitimacy of regulating bodies (in this case WADA) and lead to skepticism regarding the credibility of sanctions (Efverström et al 2016). The implications of the fragmented response to the Russia situation were acknowledged by Frédéric Donzé, WADA Chief Operating Officer:

'There was a disjointed response and in terms of clarity and anti-doping, it is probably detrimental when you have different organisations making different decisions' (WADA Interview 2017).

In contrast to WADA, the FATF has the authority to impose sanctions upon member states. Initially, non-compliant governments receive a letter from the FATF President. In more serious circumstances, the FATF recommends that financial organisations worldwide closely examine all transactions of resident individuals, organisations and 
financial institutions of the respective country. The most severe sanction is to suspend the non-compliant country from the FATF (FATF 2018). Given that the FATF rarely executes its authority to impose member suspensions, the sanction lacks credibility (Tsingou 2010). In contrast, the RUSI representative perceived the threat of close financial inspection as a 'strong incentive for countries to take action' (RUSI Interview 2017). In particular, the sanction promotes calculated compliance; the costs of compliance outweigh the potential costs of reduced financial flow and loss financial integrity caused by financial scrutiny. Furthermore, where sanctions are imposed, the FATF's sanctioning powers ensure a unified response to noncompliance. To prevent fragmented responses to non-compliance and enhance the effectiveness of the anti-doping regime's non-compliance response system, similar to the FATF, WADA needs the authority to impose sanctions. Andy Parkinson, former UKAD Chief Executive agreed: 'you cannot effectively have a compliance regime unless you are able to impose consequences' (UKAD Interview 2017). Although this strategy has the potential to counter credibility issues and reduce WADA's dependence upon other ADOs, it is unlikely to receive support in the near future. As argued by the Institute of National Anti-Doping Organisations (iNADO), the IOC is reluctant to relinquish its control within the anti-doping regime (iNADO 2017). This view was shared by Andy Parkinson, former UKAD Chief Executive: 'politically, it is particularly unsavoury for the IOC to have anyone impose consequences other than themselves' (UKAD Interview 2017).

\section{Cultural Variations}

Within the analysed regimes, compliance has also been hindered by cultural variations. First, challenges have arisen due to the cultural context within which the primary rule systems were developed. Modern sport, including anti-doping regulations such as the Code, are constructs of the First World that are imposed upon other countries (Park 2005). This view was shared by Andy Parkinson, former UKAD Chief Executive:

\footnotetext{
'Anti-doping policy is largely driven by English speaking nations. Everyone is looking at it from a Western culture, versus embracing a total global culture' (UKAD Interview 2017).
} 
Similarly, the FATF Recommendations are constructs substantially of the Western world that are imposed upon non-Western cultures (Alkaabi et al 2014). As the contextual circumstances become more distant from the Western norm, the relevance of Articles contained within an international agreement decreases (Ansell 2014). Assumptions regarding the homogeneity of value reference points have created challenges in terms of translating Western conceptualisations contained within Conventions into non-Western cultures. In the anti-doping regime, the idea that doping contradicts the spirit of sport lies at the heart of anti-doping policy and the Code (WADA Code 2015). However, Houlihan et al (2017) found variations between the reference points used in the UK and Japan when deciding upon the morality of sporting behaviours, including doping. Whereas UK respondents referred to values specific to the sporting context, Japanese respondents primarily referred to wider social values. Similarly, the anti-money laundering regime has struggled to institutionalise international norms. The 'Know Your Customer' norm requires financial and relevant non-financial institutions to verify an account holder's identity. However, in some countries, cultural traditions and national interpretations have weakened the norm's salience. For example, the UAE's cultural tradition values extended family relationships and close family ties. Consequently, there is a concern that within such countries, front line employees within financial organisations often fail to conduct and comply with due diligence procedures (Alkaabi et al 2014). Similar cultural problems exist within the child rights regime; the type of child imagined within the UNCRC is western, middle-class and able-bodied (Ansell 2014). Different geographical and cultural contexts affect the way in which international agreements are absorbed and interpreted. The analysed regimes therefore face a similar challenge; ensuring that international standards developed in a Western cultural context are effectively translated and embedded into contrasting non-Western cultures.

Second, the anti-doping regime is challenged with navigating national, in addition to sporting, cultures. The issue was emphasised by Frédéric Donzé, WADA Chief Operating Officer: 'in some sports and regions, there is a culture that is less prone to anti-doping or clean sport' (WADA Interview 2017). At the national level, the revelation of institutionalised cheating in Russia highlighted the extent to which 
national cultures and interests may conflict with international anti-doping norms (McLaren Report 2016). The revelation emphasised that implementation structures do not guarantee compliance and good governance. At the sporting level, individual sporting cultures are characterised by shared values, expectations and practices, each of which governs the acceptability of specific behaviours, including doping (Whitaker et al 2014). Similarly, various cultures, specifically national and organisational cultures, exist within the anti-money laundering regime. Switzerland's long history of private banking and bank secrecy has embedded a culture of non-intervention within many Swiss financial organisations. More generally, the financial industry is largely characterised by a professional culture of non-intervention in financial operations (Tsingou 2010). Although cultures have the potential to impact compliance, it is difficult to develop an appropriate compliance measurement system that is able to provide an accurate measure of the depth of commitment. Nevertheless, at the national level within the anti-money laundering regime, efforts have been taken to discover non-compliance. In addition to intelligence led audits, the UK Financial Conduct Authority (FCA) conducts random audits and is empowered to conduct unannounced organisational inspections (FCA 2016). Although WADA recently introduced audits of NADOs and IFs, similar to the FCA, compliance monitoring could include random and unannounced inspections of ADOs.

Third, cultural norms impact the effectiveness of the compliance information system, particularly whistleblowing. Negativity towards whistleblowing is evident at the national level. This problem was emphasised by Herman Ram, Dutch Doping Authority CEO: 'fundamentally, the culture is against whistleblowers, snitching in The Netherlands is looked upon very negatively' (Dutch Doping Authority Interview 2017). With reference to the athlete community, a recent study (Whitaker et al 2014) found that a code of silence is deeply embedded and protects athletes who dope from exposure and punishment. The extent to which the norm of silence has been embedded was found to vary according to different sports. Compared to track and field athletes, rugby league players were more likely to adopt the morality of loyalty and adhere to a code of silence. This result was explained through the importance of team cohesion within team sports, which contributes towards increased feelings of loyalty. Within other sports, athletes are reluctant to come forward due to fear of isolation by teammates. In cycling, where the culture is arguably supportive of 
doping, the fear of ostracization discourages whistleblowing (Hardie et al 2012). Although WADA has recently invested in whistleblowing platforms such as Speak Up, a secure online platform through which athletes and other persons can anonymously report anti-doping violations, to enhance the effectiveness of whistleblowing, organisations at all levels of implementation must develop strategies that focus upon changing, albeit slowly, the code of silence that exists in certain sporting and national cultures. Cultural norms cause similar challenges within the anti-money laundering regime; ideals surrounding privacy and confidentiality rights discourage whistleblowers from coming forward and often lead to superficial levels of compliance amongst banking officials. Consequently, national and cultural norms promote a code of silence create challenges in terms of cultivating a whistleblowing culture (Tsingou 2010).

In addition to a supportive culture, legislation that protects whistleblowers from retributive action encourages whistleblowing. Yaya Yamamoto, JADA Senior Manager agreed: 'we need to protect athletes to create a culture of speaking out' (JADA Interview 2017). Article 10.6.1 of the Code states that it is possible for athletes who provide substantial assistance that results in an anti-doping rule violation to receive a reduction in their sanction (WADA Code 2005). Section 3.3 of WADA's whistleblowing programme also states that whistleblowers will be provided anonymity and protected from retaliation (WADA 2016). Nevertheless, WADA has previously found it difficult to foster a culture that is supportive of whistleblowers. Frequently, athletes have expressed concern that compared to athletes who dope, whistleblowers are subject to harsher treatment and isolation (Pound Report 2012). Furthermore, despite Article 10.6.1 of the Code, the IOC treated Yuliya Stepanova (the whistleblower who provided evidence of institutionalised doping in Russia) poorly and refused her participation at the Rio 2016 Olympic Games (Duval 2016).

\section{Resource Constraints}

After the top-down implementation approach and cultural variations, resource constraints (particularly financial constraints) were identified as the third recurrent factor that hindered compliance in the anti-doping and anti-money laundering 
regimes. With reference to WADA's financial capacity, WADA is equally funded by the Olympic Movement and governments. Insufficient funding has placed constraints upon anti-doping activities. In 2016, WADA's annual budget was US \$28.3 million (WADA 2016). To put WADA's budget into perspective, the figure is dwarfed by the annual value of the global sports industry, which was estimated at US \$145 billion in 2015 (PWC 2015). Tim Ricketts, WADA Director of Standards and Harmonisation recognised the resource constraints and stated that WADA is 'looking at our fellow stakeholders to step in and help out' (WADA Interview 2017). Additional financial support was provided after WADA appealed for increased funding following the revelation of institutionalised doping in Russia; the French and Polish governments contributed US $\$ 159,544$ and US $\$ 50,000$ respectively (WADA 2017). WADA's President also called upon sponsors and broadcasters to consider contributing funds to the anti-doping cause. Sports sponsors, broadcasters and major event organisers have an interest in, and benefit from, clean sport. As a result, arguably, they have a responsibility to provide additional funding for anti-doping activities (Müller 2017). Despite the mismatch between the investment in doping and the global value of sport, WADA has struggled to persuade broadcasters and sponsors to commit money to the fight against doping. In contrast to WADA, Anders Solheim, ADN Chief Executive, perceived broadcaster revenue as an unrealistic strategy: 'I do not think broadcasters will pay the money to WADA, that is a long way away' (ADN Interview 2017). Whilst the anti-doping interviewees did not foresee funding from commercial partners as a realistic strategy for the immediate future, sponsors were identified as potential advocates of clean sport. Jeremy Luke, Director of Anti-Doping at CCES suggested:

'Sponsors could become more of an advocate by saying if we are going to enter into an arrangement with you, you need a quality anti-doping programme in place' (CCES Interview 2017).

In recognition of the need to increase its financial capacity, WADA has announced plans to pursue additional funding strategies that target private donors, corporations and foundations (WADA 2016). Similar funding strategies are used within the child rights regime; UNICEF is not in receipt of UN funding and instead relies upon voluntary contributions from corporations, foundations and private individuals (UNICEF 2018). 
At various levels of anti-doping implementation, resources restrict the ability of countries and ADOs to deliver an effective anti-doping programme and comply with the Code (Houlihan 2013). As government funded organisations, NADOs are dependent upon the government for resources. However, significant variations exist between the ability and the willingness of governments to commit resources to antidoping. During the 2015-2016 period, UKAD had an annual budget of $£ 5.4$ million, whilst the Jamaican Anti-Doping Organisation had a budget of $£ 81,000$ (Butler 2015). Additionally, as a result of resource limitations, many African, Eastern and Central European NADOs do not have the capacity to comply (Houlihan 2013). National priorities also constrain anti-doping resources. Herman Ram, Dutch Doping Authority CEO shared this view:

'In developing countries, in Syria or the Palestine territories, governments have other business to attend to and that is more than understandable it is completely logical' (Dutch Doping Authority Interview 2017).

Furthermore, it is important to recognise that where resources are concerned, even the wealthiest of ADOs face challenges in terms of implementing and monitoring compliance with the Code. Herman Ram, Dutch Doping Authority CEO agreed: 'the Code demands much more than even the most developed NADOs can realise' (Dutch Doping Authority Interview 2017). Therefore, although a genuine commitment to compliance may exist, insufficient resources inadvertently cause non-compliance. An alternative perspective is that a facade of compliance is presented and that a lack of political commitment has resulted in deliberate under-resourcing. Anders Solheim, ADN Chief Executive agreed with the latter perspective:

'It is a lack of commitment in some countries because they can send a huge number of athletes to the Olympic Games, so there is some money available’ (ADN Interview 2017).

With reference to the financial capacity of IFs, Mountjoy et al (2017) revealed significant variations between the annual budgets of summer Olympic IFs. During 2015, the annual anti-doping expenditure of six IFs exceeded US \$1 million and 
accounted for $80 \%$ of overall spending. In contrast, the annual expenditure of seventeen IFs was less than US $\$ 300,000$. In addition to financial constraints, the ability of ADOs to comply is often hindered by lack of expertise. This problem was identified in the 2016 Rio Olympic Games IO Report; insufficient levels of expertise amongst chaperones and doping control officers was identified as a factor that contributed to the failure of the Olympic anti-doping programme (IO Report 2016). Where resource limitations place constraints upon policy delivery, employees may resort to their developed coping mechanisms (Lipsky, 1978). Within the anti-money laundering regime, many private organisations have used compliance requirements as an opportunity to consolidate the expertise of staff (Tsingou 2010). Likewise, to enhance the effectiveness of anti-doping programmes and improve compliance, ADOs must ensure that staff have relevant expertise.

\section{Capacity Building to Alleviate Resource Constraints}

Where non-compliance is caused by resource constraints, capacity building has the potential to be more effective than sanctions (Houlihan 2013). Established in 2008, UNECSO's Fund for the Elimination of Doping in Sport provides capacity building opportunities; state parties may apply for a national grant up to US $\$ 20,000$, or a regional grant up to US $\$ 50,000$ for projects focusing upon capacity building, policy advice or education programmes that target youths and sport organisations. Between 2008 and 2017, the Fund had invested over US \$4.2 million in 218 projects involving 108 state parties (36 projects related to capacity building). However, the Fund is reliant upon the voluntary contributions of member states and private organisations. Despite 185 signatories to the UNESCO Convention Against Doping in Sport, between 2007 and 2017, only 21 countries contributed to the Fund. The Fund's potential to provide aid is also dwindling as voluntary contributions have recently declined (UNESCO 2017). Similar to UNESCO, in 2009 the IMF established a donor fund to finance capacity development within the anti-money laundering regime. Whereas UNESCO invested US \$4.2 million into capacity building during its first ten years, the IMF Fund's annual direct spend on capacity building is US \$6.5 million. The IMF's ability to maintain donor contributions is attributed to the IMF's intensive outreach efforts, which emphasise the strengths and efficiency of the capacity building programme (IMF 2016). To address the decline in the UNESCO Fund 
contributions, UNESCO could use a similar strategy to target current donors, in addition to new public and private bodies within the anti-doping regime.

Müller (2017) emphasised the importance of capacity building through cooperation between countries with established, and countries with developing, anti-doping systems. Bilateral agreements aim to achieve deeper levels of compliance through mimetic isomorphism. Mimetic isomorphism refers to the process where an organisation (in this case a NADO), undergoes institutional change to resemble successful actors (in this case another NADO). To assist the implementation of bilateral agreements, in 2014, WADA published guidelines for the development of NADO to NADO partnerships. Within the anti-doping regime, Norway has engaged in a number of bilateral agreements. Inter-governmental agreements have occurred between Norway and China, Cuba, Denmark, France, Russia and South Africa. At the organisational level, ADN supported the development of Greece and Japan's NADOs, cooperated with Poland to develop an international doping control team and worked with the Russian Anti-Doping Agency to develop international testing standards (Hanstad and Houlihan 2015). However, although a number of NADO to NADO collaborations exist, there are minimal bilateral agreements between IFs. The need to expand collaborations was recognised by Tim Ricketts, WADA Director of Standards and Harmonisation, who added that WADA is 'looking to broaden the agreements with IFs being involved with other IFs' (WADA Interview 2017). Bilateral agreements designed to provide technical assistance are an important component of the anti-money laundering regime. Recently, one of the FATF's regional bodies, the Eastern and Southern Africa Anti-Money Laundering Group (ESAAMLG), established the Donors Coordination Group (DCG). Comprising representatives from all ESAAMLG members and supporting actors such as the IMF, World Bank, the UK and the USA, the DCG aims to map, coordinate and evaluate the effectiveness of technical assistance agreements involving ESAAMLG members (FATF 2018). Similar to the FATF's regional bodies, WADA's regional offices could play an enhanced role in terms of monitoring and evaluating bilateral agreements within their respective regions. However, although bilateral agreements have the potential to achieve deeper levels of compliance, a multi-faceted response system is essential to effectively address the variable causes of non-compliance (Houlihan 2013). 


\section{Conclusion}

Three key factors hinder compliance with the Code and the FATF recommendations: the top-down approach to implementation, cultural variations and resource constraints. To minimise the problems incurred by each factor and enhance Code compliance, a number of strategies may be implemented by the anti-doping regime. To strengthen the top-down implementation framework, similar to the FATF, WADA needs to be empowered with the authority to impose sanctions. Although unlikely to receive support in the near future, this strategy has the potential to enhance the effectiveness of the non-compliance response system. In particular, variations in rule enforcement, which have previously undermined the legitimacy of the anti-doping regime, could be reduced. To address cultural variations, particularly the code of silence, WADA must develop strategies that focus on developing, albeit slowly, a supportive culture of whistleblowing. One approach to encourage whistleblowing is improved treatment of whistleblowers. To enhance the effectiveness of the compliance information system, similar to the FCA, WADA's compliance monitoring could include random, unannounced inspections of ADOs. Various strategies could alleviate the anti-doping resource constraints. Although the anti-doping interviewees did not foresee funding from commercial partners as a realistic strategy for the immediate future, it is important that WADA continues its attempt to secure alternative income. To ensure the sustainability of the UNESCO Fund, UNESCO should also consider diversifying its funding sources. Similar to the IMF, UNESCO could use intensive marketing campaigns that emphasise the strengths and efficiency of the Fund to target current and new public / private bodies. From a capacity building perspective, the anti-doping regime would benefit from increased implementation of bilateral agreements, particularly amongst IFs. Similar to the FATF regional bodies, an opportunity exists for WADA's regional offices to play an enhanced role in terms of monitoring and evaluating the effectiveness of bilateral agreements within their respective regions. Although the strategies may have modest and variable success in improving compliance, they possess the potential to address the problems of achieving compliance with the WADA Code.

\section{References}


Ansell, N., 2014. The convention on the rights of the child: advancing social justice for African children. In: A, Imoh and N, Ansell, eds. Children's lives in an era of children's rights. London: Routledge, 228-246.

Alkaabi, A., Mohay, G., McCullagh, A., and Chantler, N., 2010. Money laundering and FATF compliance by the international community. In: J. Berleur, M. Hercheui and M. Hilty, eds. What kind of society? Berlin: Springer, 86-97.

Batt, A., 2011. The role of UK anti-doping in the fight against doping in sport. International journal of sport policy and politics, 3 (2), 261-270.

Bloodworth, A., and McNamee, M., 2010. Clean olympians? doping and anti-doping: the views of talented young british athletes. The international journal on drug policy, 21 (4), 276-282.

Braun, V., and Clarke, V., 2006. Using thematic analysis in psychology. Qualitative research in psychology, 3 (2), 77-101.

Bryman, A., 2008. Social research methods. $3^{\text {rd }}$ ed. New York: Oxford University Press.

Butler, N., 2015. Jamaican sports minister cuts funding [online]. Inside the Games Website. 7 March. Available from: https://www.insidethegames.biz/articles/1026003/jamaican-sports-minister-cuts-antidoping-budget-by-j-14-million. [Accessed 29 May 2017].

Cooren, F., 2004. Textual agency: how texts do things in organisational settings. Organisation, 11 (3), 373-393.

Downs, G., and Trento, A., 2004. Conceptual issues surrounding the compliance gap. In: E, Luck and M, Doyle, eds. International law and organisation: closing the compliance gap. USA: Rowen and Littlefield Publishers, 91-40.

Duval, A., Ram, H., Viret, M., Wisnosky, E., Jacobs, H., and Morgan, M., 2016. The world anti-doping code 2015: asser international sports law blog symposium. The international sports law journal, 16 (1-2), 99-117.

Efverström, A., Bäckström, A., Ahmadi, N., and Hoff, D., 2016. Context and conditions for a level playing field: elite athletes' perspectives on anti-doping in practice. Performance enhancement and health, 5 (2), 77-85.

FATF, 2018. About [online]. Available from: http://www.fatf-gafi.org/about/. [Accessed 13 February 2018].

FCA, 2016. Incentivising compliance with financial regulation [online]. FCA website.

16 December. Available from: https://www.fca.org.uk/publication/occasionalpapers/op16-25.pdf. [Accessed 20 August 2018]. 
Gunn, L., 1978. Why is implementation so difficult? Management services in government, 33 (4), 169-176.

Guo, B., and Teng, C., 2012. Taiwan and the rise of china. USA: Lexington Books.

Hanstad, D., and Houlihan, B., 2015. Strengthening global anti-doping policy through bilateral collaboration: the example of Norway and China. International journal of sport policy, 7 (4), 587-604.

Hanstad, D., and Loland, S., 2005. What is efficient doping control? Norway: Norwegian School of Sport Sciences / Anti-Doping Norway.

Hardie, M., Shilbury, D., Ware, I., and Bozzie, C., 2012. I wish I was 21 now. Victoria: Auskadi Samizda.

Hjern, B., and Porter, D., 1981. Implementation structures: a new unit of administrative analysis. Organisational studies, 2 (3), 211-227.

Houlihan, B., 2013. Achieving compliance in international anti-doping policy: an analysis of the 2009 world anti-doping code. Sport management review, 17 (3), 265276.

Houlihan, B., Downward, P., and Rasciute, S., 2017. Anti-doping regulations and the significance of public opinion: an analysis of public opinion in japan and the UK on issues of fairness and integrity in sport. Loughborough: Loughborough University.

Huybers, T., and Mazanov, J., 2012. What would kim do: a choice study of projected athlete doping considerations. Journal of sport management, 26 (4), 332-334.

IAAF, 2017. World U18 championships [online]. IAAF, Monaco. Available from: https://www.iaaf.org/competitions/iaaf-world-u18-championships/iaaf-world-u18championships-nairobi-2017-5838/medaltable. [Accessed 17 August 2018].

IMF, 2016. IMF and the fight against money laundering [online]. IMF, Washington DC. Available from: http://www.imf.org/external/np/exr/facts/aml.htm/septermber2009. [Accessed 29 November 2017].

IOC, 2016. Executive board decision [online]. IOC press release. 24 July. Available from: https://www.olympic.org/news/decision-of-the-ioc-executive-boardconcerning-the-participation-of-russian-athletes-in-the-olympic-games-rio-2016.

[Accessed 29 November 2017].

IO report, 2016. Games of the XXX1 olympiad. IOC, Lausanne.

Krasner, S., 1982. Structural causes and regime consequences: regimes as intervening variables. International organisation, 36 (2), 185-205. 
Lipksy, M., 1978. Standing the study of policy implementation on its head. In: W, Burnham and M, Weinberg, eds. American politics and public policy. Massachusetts: MIT Press, 391-402.

Lipicer, S., and McArdle, D., 2014. National law, domestic governance and global policy: a cast study of anti-doping policy in Slovenia. International journal of sport policy and politics, 6 (1), 71-87.

Mclaren, R., 2016. WADA investigations of Sochi allegations [online]. Montreal, WADA. Available from: https://www.wadaama.org/sites/default/files/resources/files/20160718_ip_report_newfinal.pdf.

[Accessed 20 January 2018].

Mitchell, R., and Chayes, A., 1995. Improving compliance with climate change treaty. In: H, Lee, ed. Shaping national responses to climate change. Washington DC: Island Press, 115-146.

Mountjoy, M., Miller, S., Vallini, M., Foster, J., and Carr, J., 2017. International sports federation's fight to protect the clean athlete: are we doing enough in the fight against doping? British journal of sports medicine, 0 (0), 1-2.

Müller, D., 2017. How to protect the clean athletes? German journal of exercise and sport research, 47 (3), 1-11.

Overbye, M., Knudsen, M., and Pfister, G., 2013. To dope or not to dope: elite athletes' perceptions of doping deterrents and incentives. Performance enhancement and health, 2 (3), 119-134.

Park, J., 2005. Governing doped bodies: the world anti-doping agency and the global culture of surveillance. Critical methodologies, 5 (2), 174-188.

Pound, R., Ayotte, C., Parkinson, A., Pengilly, A., and Ryan, A., 2012. Report to WADA executive committee on lack of effectiveness of testing programs. Montreal, WADA.

Prior, L., 2008. Repositioning documents in social research. Sociology, 42 (5), 821836.

PWC, 2015. Outlook for the global sports market [online]. PWC report. Available from: $\quad \mathrm{https} / / / \mathrm{www} . \mathrm{pwc} . c \mathrm{~m} / \mathrm{gx} / \mathrm{en} /$ industries/hospitalityleisure/publications/changing-the-game-outlook-for-the-global-sports-market-to2015.html. [Accessed 17 August 2018].

Raustiala, K., and Slaughter, A., 2013. International law, international relations and compliance. In: T, Risse, C, Ropp, and K, Sikkink, eds. The persistent power of human rights. Cambridge: Cambridge University Press, 538-558.

Ritchie, I., and Jackson, G., 2014. Politics and 'shock': reactionary anti-doping policy objectives in Canadian and international sport. International journal of sport policy and politics, 6 (2), 195-212. 
Trachtman, J., 2010. International law and domestic political coalitions: the grand theory of compliance with international law. Chicago journal of international law, 11 (1), 127-158.

Tsingou, E., 2010. Global financial governance and the developing anti-money laundering regime: what lessons for international political economy? International politics, 47 (6), 617-637.

UNESCO, 2017. Evaluation of UNESCO's international convention against doping in sport [online]. UNESCO, Paris. Available from: http://www.unesco.org/new/fileadmin/MULTIMEDIA/HQ/IOS/images/Terms_Of_R eference_Evaluation_of_the_AntiDoping_Conventi.pdf. [Accessed 17 August 2018].

UNICEF, 2015. UNICEF's work [online]. UNICEF, New York. Available from: https://www.unicef.org/publicpartnerships/66662_66849.html [Accessed 22 June 2018].

WADA, 2016. Annual report. Montreal, WADA.

WADA, 2017. Wada accepts additional funding [online]. Montreal, WADA. Available from: https://www.wada-ama.org/en/media/news/2017-03/wada-welcomesadditional-usd-50000-contribution-from-the-republic-of-poland. [Accessed 29 November 2017].

WADA Code, 2015. 2015 Anti-Doping Code. Montreal, WADA.

Wagner, U., 2011. Towards the construction of the world anti-doping agency: analysing the approaches of FIFA and the IAAF to doping in sport. European sport management quarterly, 11 (5), 445-470.

Wagner, U., and Hanstad, D., 2011. Scandinavian perspectives on doping - a comparative policy analysis in relation to the international process of institutionalising anti-doping. International journal of sport policy and politics, 3 (3), $355-372$.

Whitaker, L., Backhouse, S., and Long, J., 2014. Reporting doping in sport: national level athlete's perceptions of their role in doping prevention. Scandinavian journal of medicine and science in sport, 24 (6), 515-521.

WEF, 2017. Global gender gap index. Cologny, World economic forum. 